\title{
Bibliotecas híbridas: uma análise discursiva da Biblioteca Central de Liverpool
}

\author{
Bibliotecas híbridas: un análisis discursivo de la Biblioteca Central de Liverpool
}

Hybrid libraries: a discourse analysis of the Central Library at Liverpool

\section{Rafaela Carolina da Silva, Larissa de Mello LimA, Cynthia Maria Kiyonaga SuenagA, Daniel MAR- TíNEZ-ÁvILA, João Batista Ernesto MORAES}

Universidade Estadual Paulista Júlio de Mesquita Filho, Avenida Hygino Muzzi Filho, 737, rafaelaca-rolinasilva@gmail.com, larissalima.unesp@gmail.com, cmksuenaga@gmail.com.dmartinezavi-la@marilia.unesp.br., jota@marilia.unesp.br

\begin{abstract}
Resumen
Las bibliotecas híbridas se caracterizan por permitir una mayor interacción entre el hacer profesional y los usuarios de una unidad de información. En este sentido, se presentan como nexos de información entre las bibliotecas tradicionales y las digitales. Por su mayor flexibilidad en la oferta de servicios y productos, deben estudiarse desde los auspicios de una metodología rica en postulados, que se adapten tanto a la forma como a los enunciados que se adoptan en esos ambientes. Su perspectiva social proporciona a su estructura organizacional políticas favorables para el desarrollo de comunidades, en la medida en que contribuye al buen funcionamiento de la institución. En esa perspectiva, la pregunta de investigación de este trabajo refiere al potencial que las bibliotecas híbridas ofrecen a la sociedad. Por lo tanto, el análisis de discurso basado en Orlandi, que hace una relectura de las obras de Foucault y Pêcheux en la publicidad, posibilita el análisis del discurso del archivo de la Biblioteca Central de Liverpool, en el Reino Unido. Esta institución, mediante la incorporación en su estructura otro tipo de unidad de información como es el archivo, refleja el modelo ideal de biblioteca híbrida que se aplicará en las unidades de información. El análisis encontró que la adaptación de otras unidades de información, tales como archivos, al entorno de las bibliotecas híbridas afecta a la capacidad de los usuarios de descubrir nueva información e indagar sobre la información que la biblioteca está proporcionando.
\end{abstract}

Palabras clave: Bibliotecas híbridas. Archivo de la Biblioteca Central de Liverpool. Análisis del discurso. Discurso publicitario. Reino Unido.

\section{Introdução}

A Biblioteca Central de Liverpool, no Reino Unido, destaca-se como uma referência em bibliotecas híbridas no âmbito internacional. É uma das iniciativas da Secretaria do Estado para incentivar e promover o gosto pela leitura por meio de recursos tradicionais e digitais (Oppenheim e Smithson, 1998). Em sua estrutura organizacional, os serviços e produtos oferecidos convivem com as novas tecnologias, como

\begin{abstract}
Hybrid libraries allow a greater interaction between the professional practice and the users of an information unit. In this sense, they are information links between traditional and digital libraries. Due to their greater flexibility in offering services and products, they must be studied using a rich methodology that can be adapted to the form and statements stemmed from those environments. Its social perspective provides the organizational structure with policies for the development of communities, also contributing to a good functioning of the institution. In that perspective, the research question of this paper refers to the potential of hybrid libraries for society. The discourse analysis based on Orlandi, that revises the works of Foucault and Pêcheux in advertising, enables the analysis of the discourse of the Central Library at Liverpool in the United Kingdom. This institution, through the inclusion of another information unit such as the archive, reflects the ideal of a hybrid library to be applied in other information units. The analysis found that the adaptation of other information units such as archives to the hybrid library environment affects the ability of users to discover new information and investigate the information that the library is providing.
\end{abstract}

Keywords: Hybrid libraries. Archive of the Central Library at Liverpool. Discourse analysis. Advertisement discourse. United Kingdom.

e-readers, aparelhos que possibilitam a leitura de livros eletrônicos, atendimento online e outras mídias digitais.

A instituição também se caracteriza pelo seu edifício com design arrojado, que consegue separar ambientes de estudo e de entretenimento, de modo que um não influencie no desempenho do outro. Destaca-se pelos serviços gratuitos oferecidos, pela área de jogos totalmente inovadora e pelo rico acervo que contém. 
Um dos aspectos das bibliotecas híbridas é a interação entre o microambiente da biblioteca com a população e o macro ambiente organizacional, contado como um arquivo local, proporcionando um ambiente de pesquisa documental multidisciplinar. A adaptação de outras unidades informacionais, como arquivos e museus no ambiente da biblioteca, caracteriza-a como um ambiente agregador de diferentes tipos de conteúdos e suportes, influenciando na descoberta da informação, por meio de uma riqueza de recursos que buscam incentivar os indivíduos a indagarem sobre a informação disponibilizada.

O interesse específico desta pesquisa é identificar o discurso da biblioteca híbrida em relação ao seu arquivo e a disponibilização de acesso aos documentos, com o intuito de identificar como este tipo de instituição pode contribuir em sociedades como a brasileira. A Análise desse discurso se dará por meio do enunciado presente no folder informacional da Biblioteca Central de Liverpool, sob o titulo: "Archive....".

\section{Metodologia}

A metodologia do trabalho é uma Análise de Discurso de linha francesa, seguindo autores como Foucault (1986), Pêcheux $(1975,1994)$ e Maingueneau (1999), aplicada à Ciência da Informação (Freitas, 2001; Romão, 2009; Ferrarezi \& Romão, 2010; Barros, 2014; Lima, 2015; Lima et al., 2015; Caprioli, 2016).

As preocupações discursivas aplicadas a enunciados evocam uma visão sistêmica destes, pois não há, segundo Foucault, enunciado neutro e independente. Os enunciados se apoiam, distinguem e integram em um campo de coexistências com efeitos em sucessão e uma distribuição de papéis e funções, que se relacionam com informações de dentro e de fora do enunciado.

No que diz respeito à relação entre a aplicação do método e o que queremos entender das bibliotecas híbridas utilizando a análise do discurso, é possível sinalizar que este estudo entende a Biblioteca Pública de Liverpool como um espaço em matrizes enunciativas que se cruzam, permeando a relação entre o documento impresso e o digital.

Esta metodologia torna-se adequada para o estudo dos discursos e enunciados de unidades de informação como bibliotecas ou arquivos em contextos espaço-temporais bem delimitados, na medida em que os documentos das bibliotecas híbridas nada mais são do que um conjunto de enunciados que seguem determinadas ideologias em detrimento de outras.
Delineando o cenário comum das unidades de informação vistas hoje na Europa, em especial no Reino Unido, as mesmas diferenciam-se do contexto atual de desenvolvimento das bibliotecas brasileiras, pois, no Brasil, são poucos os esforços voltados ao desenvolvimento civil e tecnológico.

\section{Bibliotecas híbridas}

O termo híbrido que, de acordo com Breaks (2002), tem suas origens na Teoria da Evolução de Darwin, designa-se como um novo modo de descrever tipos de serviços, que buscam integrar fontes tradicionais e eletrônicas de informação. O valor de uma informação se dá, então, pelas suas necessidades de uso. Portanto, é um bem comum, que deve atuar como fator de inclusão social, ou seja, como propulsora da cidadania através de sua disponibilização aos diferentes públicos presentes na sociedade. Nesse sentido, o trabalho de uma biblioteca rumo à construção da cidadania deve levar em conta os diferentes tipos de usuários e suas necessidades informacionais.

O desenvolvimento das bibliotecas híbridas começou em 1992, no Reino Unido, a partir da separação dos cursos técnicos, antes agregados às universidades e aos cursos politécnicos, onde começou-se a estudar o impacto das bibliotecas na qualidade de suas pesquisas. Esse assunto foi base para o Joint Funding Council's Libraries Review Group, que, em novembro de 1993, produziu o Follet Report, um relatório referido ao presidente da comissão, Prof. Brian Follet, no qual abrangia abordagens de sistemas e redes de infraestrutura para as bibliotecas do Reino Unido (Ershova e Hohlov, 2002).

Segundo Russel, Gardener e Miller (1999), os requisitos necessários de uma biblioteca híbrida são: providência de serviços para descoberta, localização, requisição, envio/entrega e utilização dos recursos; o fornecimento de serviços deve ser consistente tanto para recursos locais ou remotos, independentemente do tipo de seu suporte; a estrutura organizacional deve ser flexível, permitindo o desenvolvimento de novos sistemas, quando necessário; os sistemas devem basear-se em normas internacionais, permitindo o aumento do volume e o tráfego de recursos.

Dessa forma, a diferenciação entre as bibliotecas tradicionais e as híbridas, de acordo com esses autores, estão nos serviços de envio/entrega proporcionados por essas instituições, bem como no fornecimento de serviços consistentes não só em recursos locais, mas também remotos, com enfoque na diversidade de suportes. Na questão da sua flexibilidade, a 
adaptação de outras unidades informacionais, como arquivos e museus no ambiente da biblioteca, caracteriza-a como ambientes agregadores de diferentes tipos de conteúdos e suportes, influenciando na descoberta da informação por meio de uma riqueza de recursos que buscam incentivar os indivíduos a indagarem sobre a informação disponibilizada.

Além do mais, levando em conta que as necessidades de informação nascem e variam conforme as características, as circunstâncias e o meio ambiente no qual um indivíduo está inserido (Figueiredo, 1994), a biblioteca híbrida precisa estudar sua comunidade antes de desenvolver suas atividades. Assim, por meio de políticas públicas, tecnologias e estruturas organizacionais, essas instituições procuram ligar suas estratégias de trabalho ao desenvolvimento das comunidades às quais estão inseridas, buscando torná-las incluídas socialmente.

Serra e Silva (2013) dissertam que, no cenário de transformação das bibliotecas públicas, as mudanças interferem nas formas de acesso e uso da informação. O Quadro 1 mostra as diferenças que envolvem o cenário das bibliotecas tradicionais e das chamadas "Novas bibliotecas" ou bibliotecas híbridas.

Logo, as mudanças nas práticas bibliotecárias vão de encontro com a manutenção dos itens no acervo da biblioteca, exigindo uma cooperação entre metadados e banco de dados, bem como com os consórcios entre bibliotecas. Envolvem, também, as transformações entre as linguagens e os formatos das tecnologias, influenciando na aquisição e/ou licenciamento de documentos que, por sua vez, afetam as políticas de acesso ao conteúdo, demandando formas de gestão distintas para o analógico e para o digital.

\begin{tabular}{ll}
\hline Bibliotecas tradicionais & Novas bibliotecas \\
\hline Usuários presenciais & $\begin{array}{l}\text { Usuários presenciais e } \\
\text { virtuais }\end{array}$ \\
\hline Acervos textuais e impressos & $\begin{array}{l}\text { Acervos em variados } \\
\text { suportes e formatos }\end{array}$ \\
\hline Coleção limitada & $\begin{array}{l}\text { Acesso a conteúdos } \\
\text { digitais }\end{array}$ \\
\hline $\begin{array}{l}\text { Acesso a conteúdos somente } \\
\text { nos horários de } \\
\text { funcionamento }\end{array}$ & $\begin{array}{l}\text { Acesso a conteúdo 24 } \\
\text { horas por dia, } 7 \text { dias da } \\
\text { semana }\end{array}$ \\
\hline $\begin{array}{l}\text { Metadados descritivos, com } \\
\text { nenhum ou baixo uso de } \\
\text { imagens }\end{array}$ & $\begin{array}{l}\text { Inclusão de conteúdo rico } \\
\text { aos metadados }\end{array}$ \\
\hline $\begin{array}{l}\text { Atendimento a usuários } \\
\text { vinculados à instituição }\end{array}$ & $\begin{array}{l}\text { Outras possibilidades de } \\
\text { comunicação com os } \\
\text { usuários }\end{array}$ \\
\hline
\end{tabular}

Quadro I. Cenário em transformação
O modelo híbrido definido por Hodges e Lunau (1999) é visto não só como a implementação de novos produtos e serviços digitais, como também serviços tradicionais baseados no impresso. Sendo assim, a biblioteca híbrida é designada para agregar diferentes tecnologias e fontes de informação, "refletindo o estado que hoje não é completamente digital, nem completamente impresso, e utilizando tecnologias disponíveis para unir, em uma só biblioteca, o melhor dos dois mundos" (Garcez e Rados, 2002, p. 47).

Em termos de modelo híbrido, a Biblioteca Central de Liverpool, no Reino Unido, destaca-se como uma referência histórica em bibliotecas híbridas no âmbito internacional, pois faz parte do conjunto de iniciativas da Secretaria do Estado para incentivar e promover o gosto pela leitura, que se dá tanto por recursos tradicionais como digitais (Oppenheim e Smithson, 1998). Em sua estrutura organizacional, os serviços e produtos oferecidos convivem com as novas tecnologias, como e-readers, aparelhos que possibilitam a leitura de livros eletrônicos, atendimento online e outras mídias digitais.

Além disso, o microambiente da biblioteca se contextualiza com a população e o macro ambiente organizacional, contando com um arquivo local, e assim proporcionando um ambiente de pesquisa documental multidisciplinar. A Biblioteca Central de Liverpool promove, nesse cenário, a inclusão social por meio dos profissionais da instituição e pela estrutura organizacional local.

A instituição busca satisfazer as necessidades informacionais dos indivíduos e dos grupos do Consulado Central Liverpool, para que eles possam participar de forma plena na vida em comunidade, através de serviços e recursos voltados não somente ao aprendizado, mas também ao entretenimento. Para tanto, incentiva a descoberta de novos conhecimentos por meio de materiais acessíveis ao público em âmbito local e via internet.

Os usuários, assim, são recebidos em um ambiente agradável e seguro para as atividades de instrução, informação e experiências de entretenimento desenvolvidas pela biblioteca. Nesse cenário, há uma conexão entre o Consulado de Liverpool, a equipe de funcionários e os membros da comunidade, a fim de que os mesmos trabalhem em conjunto para adquirir os recursos necessários e cumprir com as metas e objetivos da biblioteca.

Nesse sentido, Biblioteca Central de Liverpool é híbrida porque, segundo os requisitos de Russel, Gardner e Miller (1999), faz parte das ações Consulado da Cidade de Liverpool; seu design e arquitetura são diferenciados de todas as de- 
mais bibliotecas públicas híbridas do Reino Unido, pois traz um caráter inovador e inclusivo da população em relação à instituição; suas informações estão disponíveis em diferentes tipos de suporte e mídia; oferece ao público um espaço acolhedor e aconchegante, como convite para seu uso; possui acervo atualizado frequentemente; trabalha com uma equipe multidisciplinar, a fim de oferecer apoio às variadas necessidades dos usuários; aceita que outros equipamentos culturais desenvolvam atividades em seu espaço físico (Allerton Library e Toxteth Library); e desenvolve serviços voltados às demandas de sua comunidade. Destaca-se que a mesma é a base das demais matrizes, que podem desenvolver atividades em seu espaço.

Suas contribuições para o desenvolvimento regional/nacional ocorrem por meio da sua relação com o Consulado da cidade; do acervo, que possui, além de materiais voltados para a pesquisa, dados históricos sobre os habitantes de Liverpool; da correlação com os órgãos governamentais e privados (hotéis de Liverpool e aeroporto) o que faz com que essa unidade de informação não apenas gerencie a informação de toda a cidade, como também auxilie a comunidade (sejam eles moradores locais ou estrangeiros) de Liverpool em suas rotas a serem traçadas pela cidade; do acesso gratuito a computadores, possuindo uma equipe treinada para ajudar as pessoas que tenham dificuldade em acessar a internet; do oferecimento de um ambiente familiar, livre e acolhedor para se descobrir livros e desfrutar das leituras, atendendo desde bebês (Programa Bookstart) a pais que frequentam a instituição, alunos que estudam para exames, pesquisadores, que utilizam-se tanto dos livros como da internet, eventos e exposições; do acesso gratuito a espaços comunitários, onde as pessoas podem conhecer e partilhar atividades sociais; da formação de grupos afins, pesquisando árvores genealógicas e a história local; das visitas às escolas para explicar o trabalho da biblioteca e convidar os alunos a irem até a instituição; da promoção de sistemas de leitura próprios e de terceiros; da promoção de atividades que estimulam as mentes dos jovens; e do ReadLiverpool, um programa que oferece acesso gratuito a livros e revistas digitais.

Desse modo, os espaços híbridos conectam pessoas, informações e processos, formando uma rede de comunicação e troca de conhecimentos. Portanto, os processos informacionais em bibliotecas híbridas devem ser capazes de levantar informações acerca do seu contexto social (usuários e tecnologias), serem eficientes na disseminação da informação, planejar e propor respostas eficientes acerca das informações geradas e requeridas à instituição (Henrique e Barbosa, 2009).

Concomitantemente com esse cenário, as bibliotecas híbridas, utilizando-se de espaços híbridos e múltiplas linguagens, permitem uma maior interação entre o fazer profissional e os usuários de uma unidade de informação. São sistemas que criam um relacionamento entre seres humanos e tecnologias, permeados pelas mídias e linguagens flexíveis, ou seja, a mistura da escrita, do som e da imagem. Sendo assim, atribuir meios de interação para os indivíduos que utilizam uma biblioteca com o panorama atual propõe um desejo de criação de sujeitos que pensam antes de aceitarem a informação que recebem. Por construção, o indivíduo inserido informacionalmente passa a expressar-se de forma a gerararem novos conhecimentos. Nesse momento, então, é o processo de cognição humana, propiciado pela unidade de informação, que está entrando em ação.

As relações entre a sociedade e a organização da informação se fazem presentes de modo a promover, à comunidade que as cerca, oportunidades de se incluir informacionalmente. Por essa razão, o conceito de bibliotecas híbridas rompe parâmetros consolidados de ver e compreender, interferindo na disseminação e geração de conhecimentos. Dessa maneira, a biblioteca híbrida é um ambiente que, por meio de sua estrutura física, inclui as tecnologias analógicas e as digitais, volta-se ao estudo de pessoas, criando uma gestão capaz de tornar os sujeitos não mais usuários, mas cooperantes e participantes dos processos de desenvolvimento político, cultural, social e tecnológico que envolvem o contexto institucional e pessoal dos indivíduos. Portanto, não é só o acesso à informação que está em jogo, como também seu uso de maneira independente, crítica e produtiva.

A Figura 1, elaborada pelos autores, mostra uma convergência entre as ferramentas tecnológicas, o fazer profissional diversificado e o usuário enquanto sujeito, não mais utilitário da informação, mas cooperante no seu uso, produção e acesso, o que promove a inclusão social de toda a comunidade organizacional. Para tanto, as bibliotecas híbridas agregam, em um mesmo ambiente, profissionais especializados para cada tipo de necessidade local (psicólogos, bibliotecários, especialistas, professores, dentre outros), com o intuito de trazer a comunidade até a instituição, por meio dos serviços oferecidos; logo, o termo biblioteca híbrida se refere tanto ao amplo compartilhamento de recursos, em entidades geograficamente dispersas, como às relações humanas, tecnológicas e sociais de uma determinada entidade. 


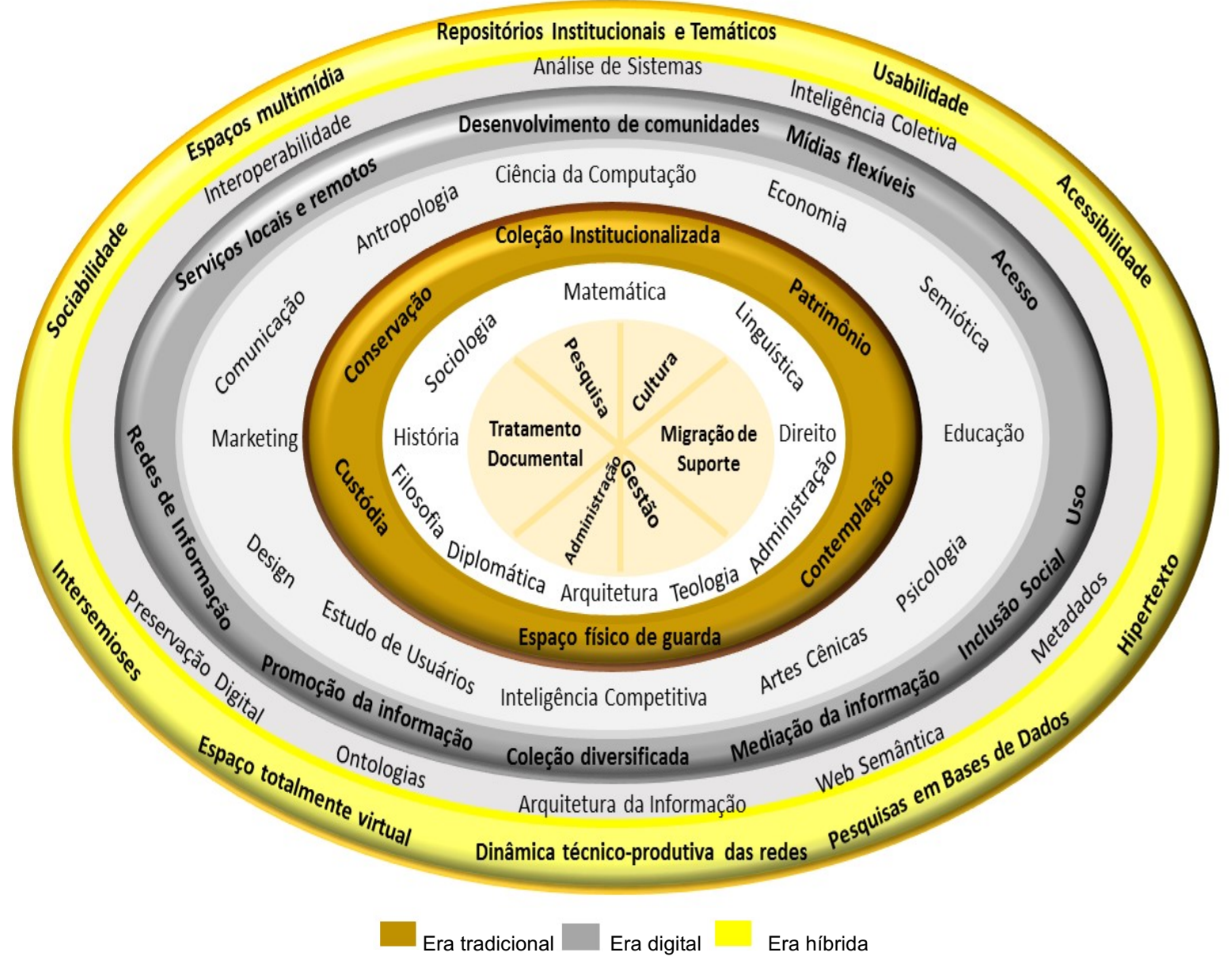

Figura 1. Do tradicional ao híbrido

Uma biblioteca híbrida parte da combinação de recursos, com base em tecnologias da informação digital e tradicional. No entanto, é mais do que simplesmente essa combinação: ela exige uma cultura que acolha a inovação em software, recursos e treinamento de usuários, auxiliandoos e respondendo suas perguntas em uma abordagem que é pró- ativa e de mente aberta.

Tais ambientes requerem uma abordagem cética, na qual nem tudo que é eletrônico é bom, e nem tudo o que está em um meio tradicional é necessariamente antiquado. Por outro lado, exigem uma visão subjetiva em se tratando dos sujeitos que se relacionam com a instituição, estudando os aspectos motivacionais e inclusivos que tornam o indivíduo cidadão - arquitetura, serviços e produtos oferecidos, relações sociais, design da informação, convergência de linguagens, bem como o aprender a aprender ao longo da vida.

São necessários dois novos conjuntos de habilidades a serem utilizados em ambientes híbridos: um deles é saber administrar o sistema de gestão de bibliotecas, configurando o cenário para trabalhar com as informações e criar estruturas adequadas ao seu uso; o outro é o trabaIho de manutenção de sistemas voltados para a eficiência e eficácia dos produtos e serviços oferecidos pela instituição. Nesse sentido, tanto a biblioteca híbrida interfere no desenvolvimento de comunidades, quanto as comunidades interferem no trabalho da biblioteca.

O bibliotecário torna-se treinador, intermediário e negociador entre fornecedores de informação, sociedade e softwares; alguém que toma a iniciativa de sugerir maneiras pelas quais a biblioteca pode ajudar sua comunidade sob o ponto de vista de uma perspectiva sociocultural. As bibliotecas híbridas são, então, uma reação das mudanças sociais que, naturalmente, implicam alternativas para justificar sua existência.

Nesse cenário, uma das principais formas de relatar tal justificativa é mostrando que esses ambientes suportam uma ampla gama de usuários em diferentes círculos culturais, de modo que se abrem ao uso público, sem distinções 
políticas, sociais, econômicas e culturais. As organizações híbridas devem compreender que são, em grande parte, impulsionadas pelo acesso a conteúdos em múltiplas fontes, tal como pelas mudanças concomitantes das necessidades dos usuários, que afetam a gama de serviços que as bibliotecas podem fornecer.

\section{Análise do discurso da Biblioteca Central de Liverpool}

Para proceder à análise, considera-se que o discurso, para o analista do discurso, é entendido enquanto produto, pois há a materialidade do enunciado ou de um grupo de enunciados que formam a "corpora" que será submetida à análise, buscando caracterizar a formação discursiva que norteia o serviço de arquivo desta biblioteca.

Mazière (2007, p. 14) expõe o papel do analista: "ele delimita, põe em correspondência, organiza fragmentos de enunciados, mais ou menos longos e mais ou menos homogêneos para submetê-los à análise".

Verificou-se que as bibliotecas de Liverpool estão, de algum modo, subordinadas à Câmara Municipal da cidade. Não há website próprio para cada biblioteca, e as 19 bibliotecas que compõem o sistema estão listadas no endereço da Câmara Municipal, que fornece o endereço, o horário de funcionamento e algumas informações adicionais sobre os serviços de cada biblioteca. Isso demonstra que a biblioteca fica subordinada às decisões do governo, que são os sujeitos responsáveis por materializar suas enunciações.

A instância enunciativa analisada é materializada no folder informacional da Biblioteca Central de Liverpool, mais especificamente o serviço de arquivo, visando compreender como a biblioteca se posiciona em relação à documentação disponibilizada para a comunidade (Liverpool.gov.uk, 2016):

É um lugar para saber mais sobre sua história, família, casa, rua ou bairro. Quem você pensa que é, de onde você acha que veio e como era a vida em Liverpool antigamente? Suas perguntas podem ser respondidas aqui. Você pode saber mais sobre as pessoas famosas de Liverpool, edifícios e eventos. Aqui há coleções fabulosas de arquivos únicos e raros do século XIII até os dias atuais. Uma equipe experiente irá ajudá-lo nesta boas-vindas [...]. O arquivo está sempre se expandindo com coleções que são continuamente adicionadas ao acervo. Nosso novo Estúdio de Conservação e nosso repositório nos ajudará a preservá-los em um ambiente altamente seguro e controlado.

O texto acima representa a seção "arquivo", conforme o folder divulgado pela Biblioteca Cen- tral de Liverpool, ou seja, o corpus que será submetido à análise na seção a seguir.

Segundo Orlandi (1999), há uma série de perguntas que norteiam a análise discursiva, fazendo-a ficar mais simples de entender em suas etapas.

\subsection{A primeira pergunta é "O que é dito neste discurso?"}

Neste discurso explicitado no folder de divulgação da Biblioteca Central de Liverpool, é possível destacar o papel do pronome possessivo "Seu/Sua". Em "sua história, (sua) família, (sua) casa, (sua) rua ou (seu) bairro" percebe-se uma estratégia de persuasão para fazer o usuário se sentir parte daquela instituição como extensão da sua própria história, família, casa, rua e bairro, ou seja, o interesse é fazer com que as pessoas se sintam totalmente à vontade dentro de um espaço público.

Paradigma este que entra em conflito com o que foi construído na mente dos cidadãos o século $X X I$, que tem muito bem demarcado a oposição entre espaço privado e o espaço institucional público. O segundo espaço como aquele que é estático, exatamente por ser delimitado pelo estado, enquanto que o espaço privado seria o local onde o indivíduo teria mais liberdade para realizar suas ações. A Biblioteca Central de Liverpool busca, então, fomentar discussões sobre o nosso modo de perceber o ambiente público e privado e, para isso, coloca a sua biblioteca como um espaço para que essas experimentações sejam feitas.

\subsection{A segunda pergunta é: "Por que isso, e não} outro?"

Ou seja, porque a Biblioteca Central de Liverpool se preocupou, de maneira detalhada, em seu folder de divulgação, em deixar marcas de uma instituição que foge aos moldes do século $\mathrm{XXI}$, fazendo com que a distinção entre os espaço público e privado ganhassem novos contornos? Talvez o caminho para esta resposta esteja na essência do que representa a biblioteca híbrida: uma biblioteca que busca equilibrar o microambiente da biblioteca e o macro ambiente institucional.

Compreender o enunciado diante da singularidade de cada situação em que cabe um discurso é percorrer um percurso não linear. Esta não linearidade é a matriz de força do enunciado, que pode ser traduzida em termos de posição "sócio-histórica na qual os enunciadores se revelam substituíveis." (Maingueneau, p. 14, 1999). 
No que tange à relação que o enunciado possui com as posições sócio históricas, Pêcheux (1994, p. 33) retoma Foucault e endossa a ideia de Maingueneau, ao pontuar que a análise de um enunciado não se restringe às descrições qualitativas sobre o dizer do sujeito.

Descrever uma formulação como enunciado não consiste, escreve Foucault, em analisar a relação entre o autor e o que ele disse (ou quis dizer, ou disse sem querer), mas sim determinar qual a posição que pode e deve ocupar todo indivíduo para ser seu sujeito. $E$ não há outros modos de ser um sujeito (Foucault, 1986, p. 33).

Proceder à análise abrange delinear alguns elementos das posições históricas e políticas do Reino Unido, nas quais a Biblioteca Central de Liverpool está diretamente vinculada às decisões do governo, no caso Câmara Municipal de Liverpool. Podemos entender essas instâncias de poder como elementos de uma formação discursiva.

Por se tratar de um folder, a perspectiva de divulgação se enquadra em um discurso publicitário que permite que haja, no mesmo plano de expressão, a ambiguidade e a polissemia, ressaltando, assim, a perspectiva lúdica e incidindo nos fenômenos de linguagem (Orlandi, 1999).

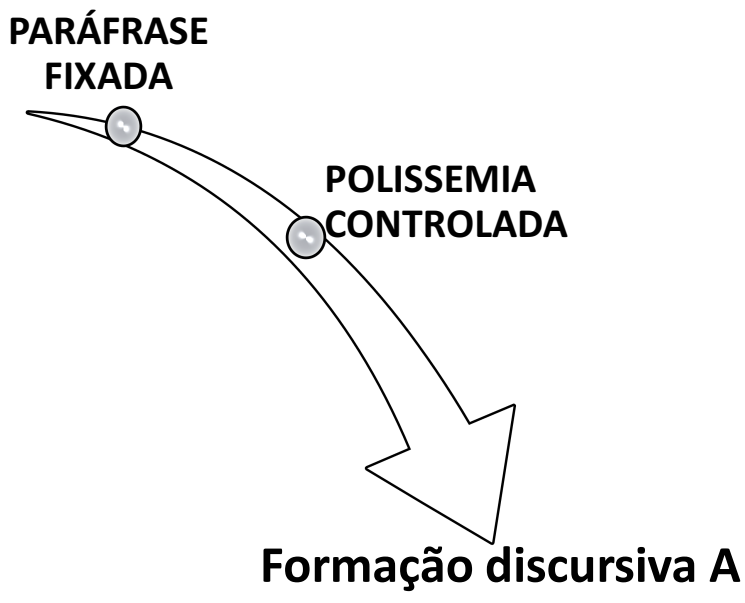

Figura 2. Plano de expressão da Biblioteca central de Liverpool

De acordo com Figura 2, é possível situar que o plano de expressão se relaciona com os processos parafrásico e polissêmico, em que a perspectiva da paráfrase é fixada nos dizeres do enunciado, na medida em que há a repetição do advérbio de localização "aqui”, sendo possível situar nas entrelinhas a perspectiva de posse, controle e, ao mesmo tempo, de autovalorização. A polissemia é controlada, por se tratar de um enunciado que busca situar interessados na perspectiva histórica da Biblioteca Central de Liverpool, ou seja, um possível pesquisador interessado na história de uma biblioteca escolar da cidade não será contemplado por conta desse jogo discursivo de controle polissêmico.

O jogo discursivo de neutralização da paráfrase e controle da polissemia culmina em uma formação discursiva denominada Formação discursiva $A$, que retoma a custódia de documentos, controle e visita guiada, mostrando, assim, que se trata de uma biblioteca restrita aos membros da comunidade de Liverpool.

\section{Resultados e discussões}

Levando-se em consideração que a proposta do estudo foi identificar o discurso da Biblioteca Central de Liverpool, que é pioneira no conceito de bibliotecas híbridas, em relação ao seu arquivo, foi possível delinear um plano de expressão que retoma um jogo enunciativo onde a polissemia é controlada por meio da paráfrase fixa, ressaltando a perspectiva de poder proporcionado pelo controle do acesso aos documentos históricos e delineando possíveis cenários políticos. A forma de acesso disponibilizada à comunidade não é explicitada no folder, mas fica claro o objetivo de disponibilizar e preservar a memória local.

A instituição demonstra em seu discurso, apresentado no folder de divulgação, o desejo de promover, nessa comunidade, a valorização histórica e cultural dos indivíduos em sociedade, dando destaque à admiração da cultura local. $\mathrm{O}$ folder é escrito em forma de discurso publicitário, em que o jogo enunciativo deixa marcas atrativas ao longo do enunciado como, por exemplo já destacado, a repetição do advérbio de localização "aqui", ressaltando sempre os pontos positivos do acesso à informação e, dessa forma, acrescentando valor ao contexto híbrido da biblioteca. Sendo assim, o discurso acrescenta valor ao contexto híbrido da biblioteca, associada ao arquivo.

Por fim, é possível ressaltar a riqueza da metodologia da Análise do Discurso, uma vez que esta trabalha com o enunciado, não se restringindo a descrições qualitativas sobre o dizer do sujeito, mas sim, referenciando a perspectiva histórica e institucional dos dizeres.

Uma formação discursiva é o que determina o que pode ou não ser dito dentro de determinado contexto, segundo Foucault (1986). Fazendo um paralelo com as bibliotecas híbridas, podemos dizer que os elementos trabalhados no Quadro 1 , que mostra a transição da biblioteca pública 
tradicional para a biblioteca híbrida, são formações discursivas que demonstram transformações, ou seja, a mudança no fazer do bibliotecário tem respaldo político, institucional e social. $\mathrm{O}$ fato de a biblioteca não contar somente com usuários presenciais, mas também virtuais, marca uma formação discursiva permeada também por acervos documentais que ultrapassam os limites dos dados impressos. O acesso a conteúdos 24 horas por dia mostra que a instituição não está mais restrita ao horário de funcionamento da biblioteca e à disponibilidade de funcionários, o que marca a formação discursiva das bibliotecas em transição do tradicional para o híbrido, dando autonomia para seus usuários e se caracterizando, inquestionavelmente, como uma ferramenta de poder social e político.

\section{Referências}

Barros, Thiago Henrique Bragato (2014). A representação da informação Arquivística: uma Análise do discurso teórico e institucional a partir dos contextos Espanhol, Canadense e Brasileiro. Marília: Universidade Estadual Paulista, 2014.

Breaks, Michael (2002). Building the hybrid library: A review of UK activities. // Learned publishing. 15:2 (2002) 99107.

Caprioli, Mariana da Silva (2016). O percurso discursivo da Ciência da Informação por meio do estudo de periódicos da área na década de 1990. Marília: Universidade Estadual Paulista, 2016.

Ershova, Tatiana; Hohlov, Yuri (2002). Libraries in the Information Society. Berlin/Munich: K.G. Saur Verlag, 2002.

Ferrarezi, Ludmila; Romão, Lucília Maria Sousa (2010). Nos labirintos da rede eletrônica: o silêncio na biblioteca escolar. // Revista ACB. 15:2 (Jul-Dec 2010) 176-193.

Figueiredo, N. M. de. (1994). Informação como ferramenta para o desenvolvimento. // Tópicos modernos em ciência da informação. Lorena: Centro Cultural Teresa D’Avila, 1994.

Freitas, Lidia Silva de (2001). Na Teia dos Sentidos: análise do discurso da Ciência da Informação sobre a atual condição da informação. São Paulo: Universidade de São Paulo, 2001.

Foucault, Michel (1986) A arqueologia do saber. Rio de Janeiro: Forense, 1986.

Garcez, Eliane Maria Stuart; Rados, Gregório J. Varvakis (2002). Biblioteca híbrida: um novo enfoque no suporte à educação a distância. // Ciência da Informação 31:2 (May/Ago 2002) 44-51. http://www.scielo.br/pdf/ci/v31n2 112907.pdf (2016-02-17).
Henrique, Luiz Cláudio Junqueira; Barbosa, Ricardo Rodrigues (2009). Busca da informação em marketing: a perspectiva da ciência da informação. Revista de Administração de Empresas 49:2 (Apr.-Jun 2009). http://www.scielo.br/scielo.php?script=sci_arttext\&pid=S 0034-75902009000200008 (2016-01-11).

Hodges, Doug; Lunau, Carrol D (1999). The national library of Canada's digital libraries initiatives. // Library Hi Tech. 17:2 (Jan 1999) 52-164.

Lima, Larissa de Mello (2015). O percurso discursivo da Ciência da Informação no Brasil: uma análise discursiva a partir dos periódicos Ciência da Informação e Revista da Escola de Biblioteconomia da UFMG. Marília: Universidade Estadual Paulista, 2015.

Lima, Larissa de Mello; Moraes, João Batista Ernesto de: Martínez-Ávila, Daniel (2015). A genealogia do conceito de Ciência da Informação no Brasil: Uma análise discursiva a partir de periódicos fundacionais na área. // Guimarães, José Augusto Chaves; Dodebei, Vera (eds.). Organização do Conhecimento e Diversidade Cultural. Marília: ISKO-Brasil; FUNDEPE, 2015. 210-218.

Liverpool.gov.br (2016). Central Library information left. http://liverpool.gov.uk/media/8252/library-info-web.pdf (2016-03-10)

Maingueneau, Dominique. (1999). Novas tendências em análise do discurso. Campinas: Pontes, 1999.

Mazière, Francine (2007). A análise do discurso: história e práticas. São Paulo: Parábola editora, 2007.

Oppenheim, Charles; Smithson, Daniel (1998). What is the hybrid library?. // Journal of Information Science. 25:2 (1998) 97-112.

Orlandi, Eni Puccinelli (1999). Análise de discurso: princípios e procedimentos. Campinas: Pontes, 1999.

Pêcheux. Michel (1975). Semântica e discurso: uma crítica à afirmação do óbvio. Campinas: Editora da UNICAMP, 1975.

Pêcheux, Michel (1994). Ler o arquivo hoje. // Orlandi, Eni Puccinelli (ed.). Gestos de Leitura: da História no discurso. Campinas: Editora da UNICAMP, 1994.

Romão, Lucília Maria Sousa (2009). Clarice Lispector - A hora da estrela: o discurso no panfleto da exposição. // Transinformação. 21:1 (Jan.-Apr 2009) 77-87.

Russel, Rosemary; Gardener, Tracy; Miller, Paul (1999) Hybrid information environments: Overview and requirements. http://www.ukoln.ac.uk/dlis/models/requir ements/overview/ (2016-01-20).

Serra, Liliana Giusti; Silva, José Fernando Modesto da (2013). Impacto dos e-books em bibliotecas e o modelo de assinatura de publicações. // Congresso Brasileiro de Biblioteconomia, Documentação e Ciência da Informação, 25. http://portal.febab.org.br/anais/article/view/ 1408/1409 (2016-03-15).

Enviado: 2016-03-31. Segunda versión: 2017-03-21. Aceptado: 2017-05-09. 